\title{
Formulation and Evaluation of Acyclovir Microspheres Pavani $\mathrm{S}^{*}, 1$, Mounika $\mathrm{K}^{*}$ and Naresh $\mathrm{K}^{*}$
}

*Department of Pharmaceutics Vaagdevi College of Pharmacy, Warangal, India .

\begin{abstract}
The present study is to formulate and evaluate Acyclovir (ACV) microspheres using natural polymers like chitosan and sodium alginate. ACV is a DNA polymerase inhibitor used in treating herpes simplex virus infection and zoster varicella infections. Acyclovir is a suitable candidate for sustainedrelease (SR) administration as a result of its dosage regimen twice or thrice a day and relatively short plasma half-life (approximately 2 to 4 hours). Microspheres of ACV were prepared by an ionic dilution method using chitosan and sodium alginate as polymers.

The prepared ACV microspheres were then subjected to FTIR, SEM, particle size, \% yield, entrapment efficiency, in vitro dissolution studies and release kinetics mechanism. The FTIR spectra's revealed that, there was no interaction between polymer and ACV. ACV microspheres were spherical in nature, which was confirmed by SEM. The particle size of microspheres was in the range of $23.8 \mu \mathrm{m}$ to $39.4 \mu \mathrm{m} .72 .9 \%$ drug entrapment efficiency was obtained in the formulation F3 (1:3 ratio) with a high concentration of calcium chloride $(4 \% \mathrm{w} / \mathrm{v})$.

The in vitro performance of ACV microspheres showed sustained release depending on the polymer concentration and concentration of calcium chloride. The release data was best fitted with zero order kinetics and Korsemeyer-Peppas release mechanism and diffusion exponent ' $\mathrm{n}$ ' value of was found to be Non-Fickian.
\end{abstract}

Keywords: Acyclovir, Microspheres, Chitosan, Sodium alginate.

\section{Introduction}

Acyclovir is a guanosine analog that acts as an antimetabolite. Acyclovir is converted by viral thymidine kinase to acyclovir mono phosphate, which is then converted by host cell kinases to acyclovir tri phosphate (ACVTP).ACV-TP, in turn, competitively inhibits and inactivates HSV-specified DNA polymerases preventing further viral DNA synthesis without affecting the normal cellular processes. Acyclovir, BCS class III drug is widely used in the treatment of herpes simplex virus infection as well as varicella zoster infection. ACV is a guanosine analogue antiviral drug. It is the one of the most commonly used antiviral drug ${ }^{(1)}$. It has short biological half-life (2-4 hours) and is usually administered orally3-4 times a day. In this work, the ionic gelation technique ${ }^{(2)}$ was used due to its simplicity, reproducibility, avoidance of organic solvents and heat. Sodium alginate and Chitosan were employed as biodegradable polymers ${ }^{(3,4)}$.

\section{Materials and Methods Materials}

Acyclovir as a gift sample was procured from Maithri Laboratories Pvt. Ltd. Chitosan was obtained from Panvo organic Pvt. Ltd, sodium alginate was Loba Chemi, Mumbai, Glacial acetic acid from TriveniInterchem Pvt.
Ltd. and Calcium chloride from TKM PharmaIndia, Secunderabad.

\section{Methods}

\section{Preformulation studies}

Preformulation testing is the first step in the rationale development of dosage forms of a drug substance. It can be defined as an investigation of physical and chemical properties of a drug substance alone and when combined with excipient. The main objective of preformulation testing is to generate useful information to the formulator in developing stable and bioavailable dosage forms.

Calibration curve for Acyclovir in $0.1 \mathrm{~N} \mathrm{HCl}$ $100 \mathrm{mg}$ of Acyclovir was dissolved in small amount of $0.1 \mathrm{~N} \mathrm{HCl}$ and shaken vigorously, then volume was made up to $100 \mathrm{ml}$ with $0.1 \mathrm{~N}$ $\mathrm{HCl}$ to obtain the primary stock solution. The necessary dilutions were made by using $0.1 \mathrm{~N}$ $\mathrm{HCl}$ to obtain the different concentrations of Acyclovir (10 to $100 \mu \mathrm{g} / \mathrm{ml}$ ). As the first step the solution is scanned on a UV scanner between 200 to $400 \mathrm{~nm}$ and the maxima peak obtained was considered as $\lambda_{\max }$. The diluted solutions prepared for calibration curve were checked for their absorbance using UV-VIS spectrophotometer at $252 \mathrm{~nm}$ against buffer as blank. Standard graph was plotted between the concentration on $\mathrm{X}$ - axis and absorbance on $\mathrm{Y}$ axis.

${ }^{1}$ Corresponding author E-mail:pavanisrm@gmail.com

Received: 30/9/2017

Accepted: 8/12/2017

Iraqi Journal of Pharmaceutical Sciences 


\section{FTIR Spectroscopy}

Identification of the chemicals procured were confirmed by FTIR Spectroscopy, in which FTIR spectrum of the sample was compared with standard FTIR spectra of the pure chemicals.

\section{Preparation of acyclovir microspheres Ionic-gelation method}

Sodium alginate solutions and chitosan solutions were prepared by dissolving $300 \mathrm{mg}$ in distilled water $(20 \mathrm{~mL})$ and $2 \% \mathrm{v} / \mathrm{v}$ aqueous acetic acid respectively. $200 \mathrm{mg}$ of drug was added to Sodium alginate solution under continuous stirring for $10 \mathrm{~min}$ to yield smooth dispersion. On the other hand required amount of calcium chloride $(2 \%$ or $4 \% \mathrm{w} / \mathrm{v})$ was added to chitosan solution. The acyclovir-alginate dispersion was taken into 23 gauge syringe and added drop wise to the chitosan-calcium chloride solution at room temperature with continuous stirring for 1-2 hours at $800 \mathrm{rpm}$ to obtain microspheres.

Then the microspheres were washed with distilled water and air dried ${ }^{(5,6)}$.

\section{Characterization of acyclovir microspheres} Surface morphology

Scanning electron microscopy (SEM) has been used to determine particle size distribution, surface topography, texture and to examine the morphology of fractured or sectioned surface. SEM studies were carried out by using HITACHI S-3700N scanning microscope. Dry Acyclovir microspheres were placed on an electron microscope brass stub. Picture of Acyclovir microspheres was taken by random scanning of the stub ${ }^{(7,8)}$.

\section{Particle size determination}

A minute quantity of Acyclovir microspheres was spread on a clean glass slide and average size of 100 Acyclovir microspheres was determined in each batch by optical microscopy in which stage micrometer was employed ${ }^{(9)}$.

\section{Determination of percentage drug entrapment} efficiency $(P D E)$

Efficiency of drug entrapment for each batch was calculated in terms of percentage drug entrapment as per the formula

Table 1. Composition of acyclovir microspheres
Practical drug content /theoretical drug content $* 100^{(10)}$.

Theoretical drug content was determined by assuming that the entire Acyclovir present in the polymer solution got entrapped in Acyclovir microspheres, and no loss occurs at any stage of preparation of Acyclovir microspheres.

Practical drug content was analyzed by dissolving $50 \mathrm{mg}$ of Acyclovir microspheres in $50 \mathrm{ml}$ of $0.1 \mathrm{~N} \mathrm{HCl}$. The solution was kept overnight for the complete dissolution of Acyclovir in diluted hydrochloric acid. This solution was filtered and further dilutions are made. The absorbance of the solutions was measured at $252 \mathrm{~nm}$ using double beam UVVisible spectrophotometer against $0.1 \mathrm{~N} \mathrm{HCl}$ as blank and the percentage of drug present in the sample was calculated ${ }^{(11)}$.

\section{Percentage yield}

Percentage practical yield is calculated to know about efficiency of any method, thus it helps in selection of appropriate method of production. Practical yield was calculated as the weight of Acyclovir microspheres recovered from each batch in relation to the amount of starting material. It is calculated by using the formula

Practical yield /theoretical yield $* 100$

\section{In vitro drug release studies}

In vitro drug release studies were performed using USP type II dissolution apparatus enclosing $900 \mathrm{ml}$ of $0.1 \mathrm{~N} \mathrm{HCl}$ medium at $50 \mathrm{rpm}$ maintaining $37 \pm 0.5^{\circ} \mathrm{C} .5 \mathrm{ml}$ sample was withdrawn at predetermined time intervals and replenished with same volume of fresh medium. The drug content in each sample was analyzed by UV- visible spectrophotometer at $\lambda_{\max } 252 \mathrm{~nm}^{(12)}$.

\section{Results and Discussion}

Microspheres of ACV were prepared by an Ionic gelation method using polymer like Chitosan and Sodium alginate. Various evaluation parameters were assessed, with a view to obtain oral controlled release of $\mathrm{ACV}$. In the present work, total seven formulations were prepared, the detailed composition is shown in table (1).

\begin{tabular}{|c|c|c|c|c|c||}
\hline \hline S. NO & $\begin{array}{c}\text { Formulation } \\
\text { code }\end{array}$ & Drug (mg) & $\begin{array}{c}\text { Sodium alginate } \\
(\mathbf{m g})\end{array}$ & $\begin{array}{c}\text { Chitosan } \\
(\mathbf{m g})\end{array}$ & $\begin{array}{c}\text { Calcium } \\
\text { chloride(\% w/v) }\end{array}$ \\
\hline $\mathbf{1}$ & S1 & 200 & 300 & 300 & 2 \\
\hline $\mathbf{2}$ & S2 & 200 & 600 & 300 & 2 \\
\hline $\mathbf{3}$ & S3 & 200 & 900 & 300 & 2 \\
\hline $\mathbf{4}$ & F1 & 200 & 300 & 300 & 4 \\
\hline $\mathbf{5}$ & F2 & 200 & 600 & 300 & 4 \\
\hline $\mathbf{6}$ & F3 & 200 & 900 & 300 & 4 \\
\hline $\mathbf{7}$ & F4 & 200 & 1200 & 300 & 4 \\
\hline
\end{tabular}


The prepared ACV microspheres were then subjected to FTIR, SEM, particle size, size distribution, \% yield, entrapment efficiency, in vitro dissolution and release kinetics. The melting point of ACV was determined using melting point apparatus and found to be $257^{\circ} \mathrm{C}$, thus indicating the purity of obtained drug sample. A standard calibration curve for the ACV was obtained by measuring absorbance at $\lambda \max 252$ in $\mathrm{pH} 1.2$ by plotting the graph of absorbance $\mathrm{v} / \mathrm{s}$ concentration which complied with standards. The standard plot of ACV is shown in figure(1).

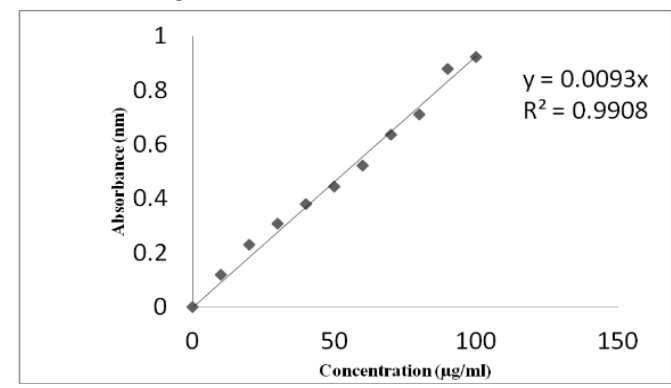

Figure 1. Standard curve of Acyclovir in 0.1 $\mathrm{N} \mathrm{HCl}$ at $\lambda$ max $252 \mathrm{~nm}$
From the spectra figure $(2,3)$ it was observed that all the characteristic peaks of ACV were present in the sample spectrum, thus indicating compatibility of ACV and other ingredients. The characteristic peaks of the ACV compared with the peaks obtained for formulation are given in table (2). There was no chemical interaction between ACV and polymer and it can be concluded that the characteristic bands of ACV were not affected after successful formulation.

Table 2. Drug polymer interaction (FTIR) study

\begin{tabular}{||c|c|c||}
\hline IR Spectra & Drug & Microspheres \\
\hline $\begin{array}{c}\text { O-H } \\
\text { stretching }\end{array}$ & 3167 & 3344 \\
\hline $\begin{array}{c}\text { C=C } \\
\text { Aromatic } \\
\text { stretching }\end{array}$ & 1482 & 1418 \\
\hline C-O-C Ether & 1045 & 1025 \\
\hline Aryl ketone & 1629 & 1604 \\
\hline
\end{tabular}

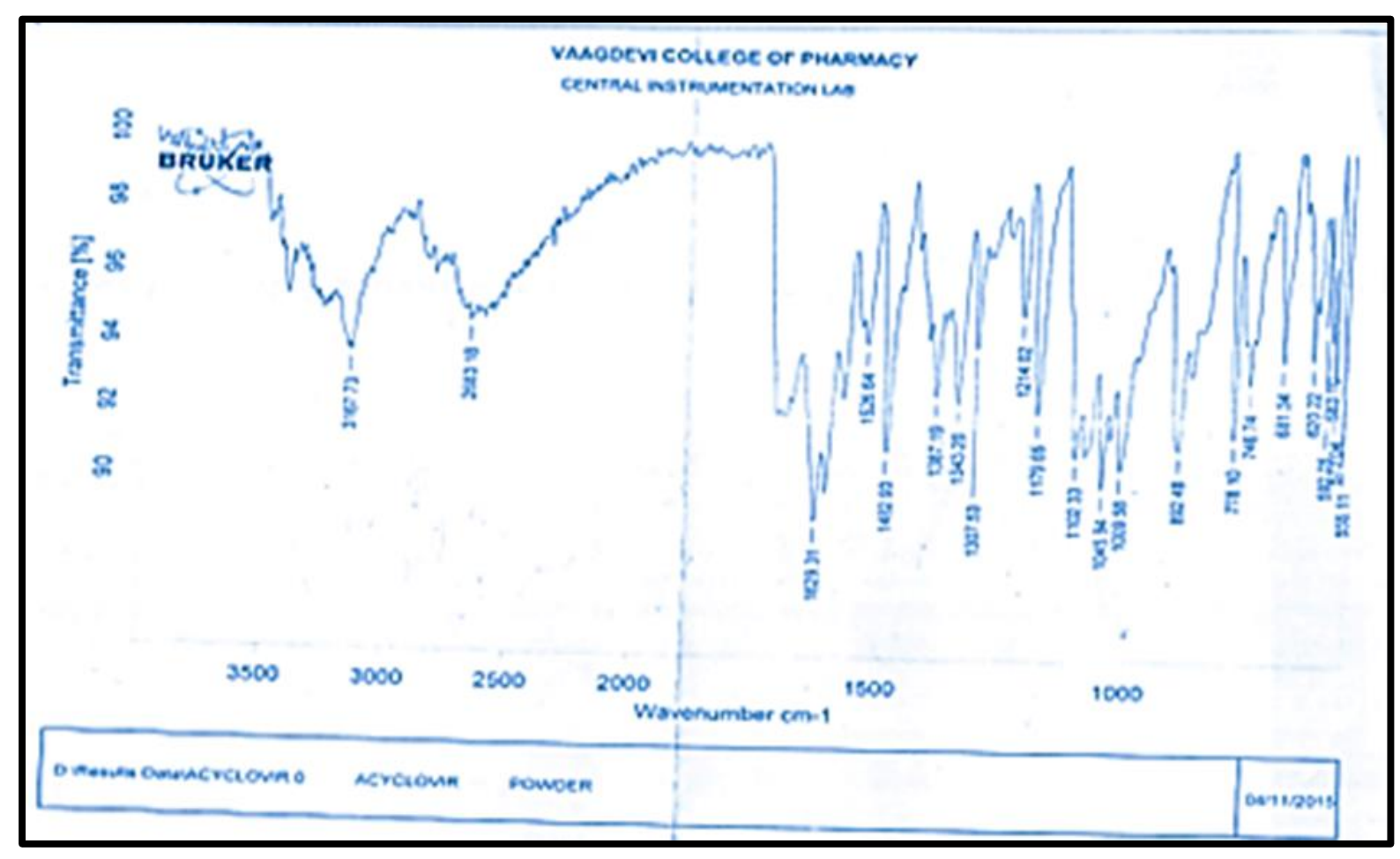

Figure 2. FTIR spectra of pure drug and microspheres 


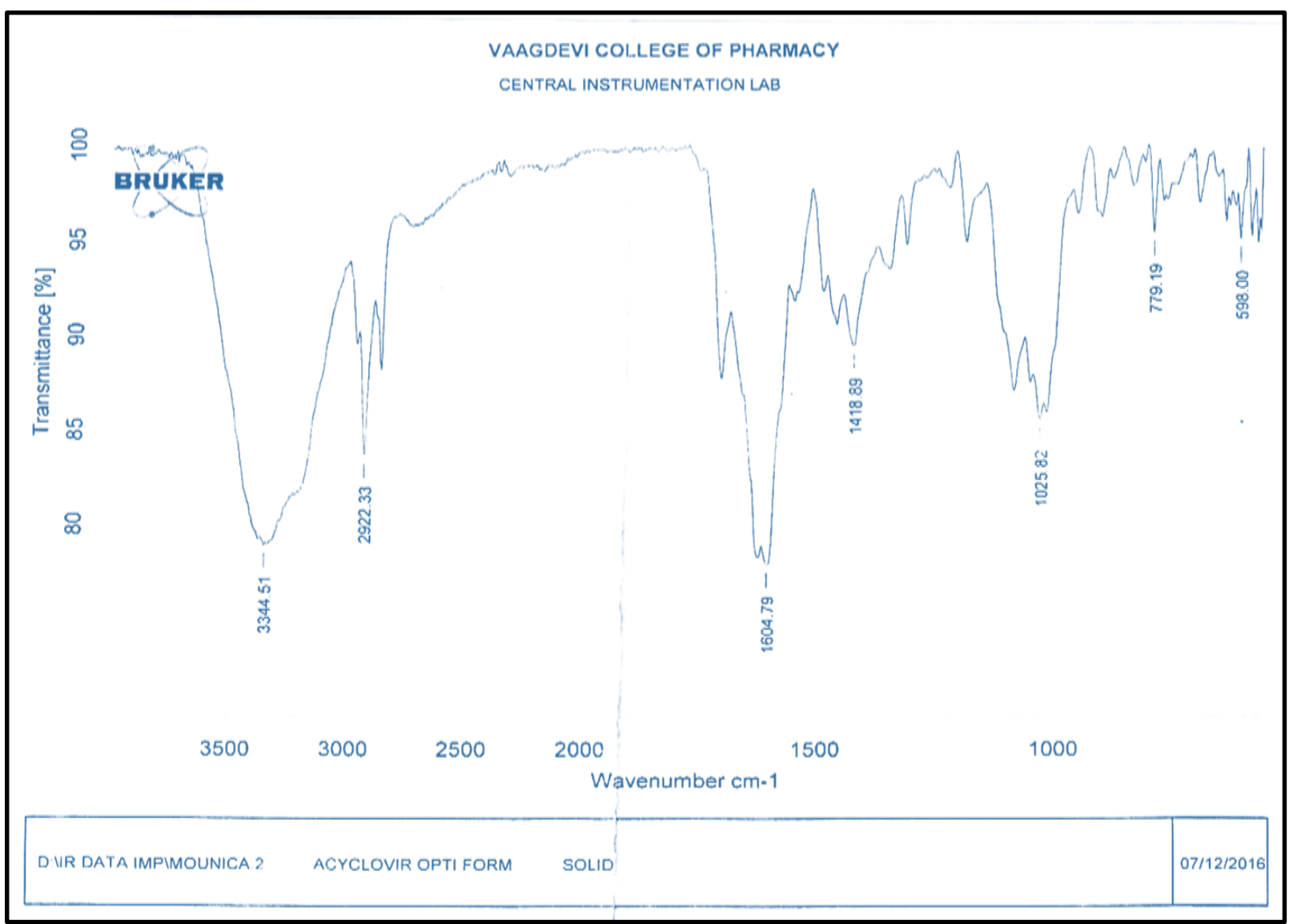

Figure 3. FTIR spectra of pure drug and microspheres

The surface morphology of the ACV microspheres was studied by SEM. SEM photographs of the optimized formulation F3 are shown in the figure (4 and 5).

The average particle size of Acyclovir microspheres was determined and results were tabulated in table (3). As polymer concentration was increased, the mean particle size of ACV microspheres was also increased. The significant increase may be because of the increase in the viscosity of the droplets (may be due to the increase in concentration of polymer solution). ACV microspheres having a size range of 23.8 to $39.4 \mu \mathrm{m}$.

Calcium chloride was used as cross linking agent, when low concentration of calcium chloride is used the entrapment efficiency was low. Entrapment efficiency increases with an increase in the calcium chloride concentration. From the results it can be inferred that there is a proper distribution of $\mathrm{ACV}$ in the microspheres and the deviation is within the acceptable limits. The percentage entrapment efficiency was found to be $38.21 \%$ to $72.9 \%$. The results obtained are given in table (3). A maximum of $72.9 \%$ drug entrapment efficiency was obtained in the F3 Formulation. It is observed that the drug entrapment was proportional to the ACV: polymer ratio and calcium chloride concentration.

The percentage yield for ACV microspheres were $52.89 \%, 57.60 \%, 76.38 \%, 56.24 \%$, $60.03 \%, 80.23 \%$ and $91.2 \%$, for formulation S1, S2, S3, F1, F2, F3, F4 respectively were given in table (3). The increase in \% yield is due to increasing in polymer concentration. The in vitro performance of ACV microspheres showed prolonged and controlled release of ACV.

The results of the in vitro dissolution studies of formulations $\mathrm{S} 1$ to $\mathrm{S} 3$ and F1 to F4 are shown in table (4) and figure $(6,7)$. 


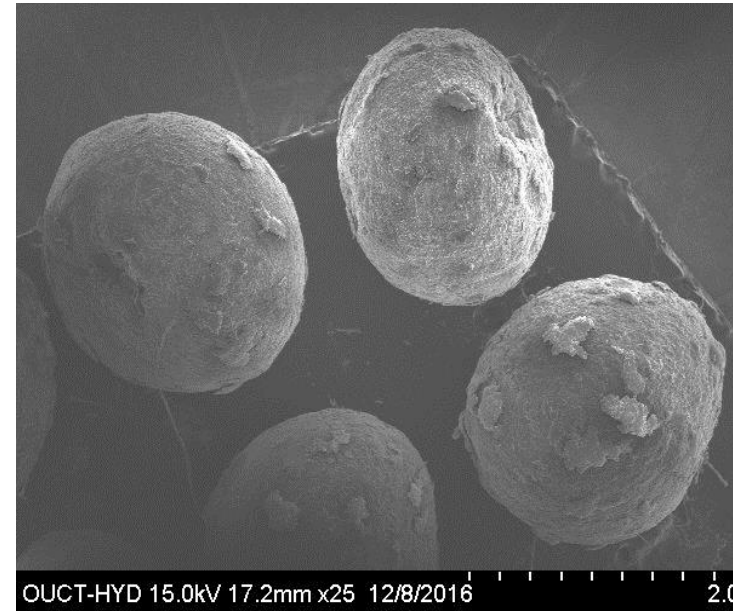

Figure. 4 SEM images of optimized formulation

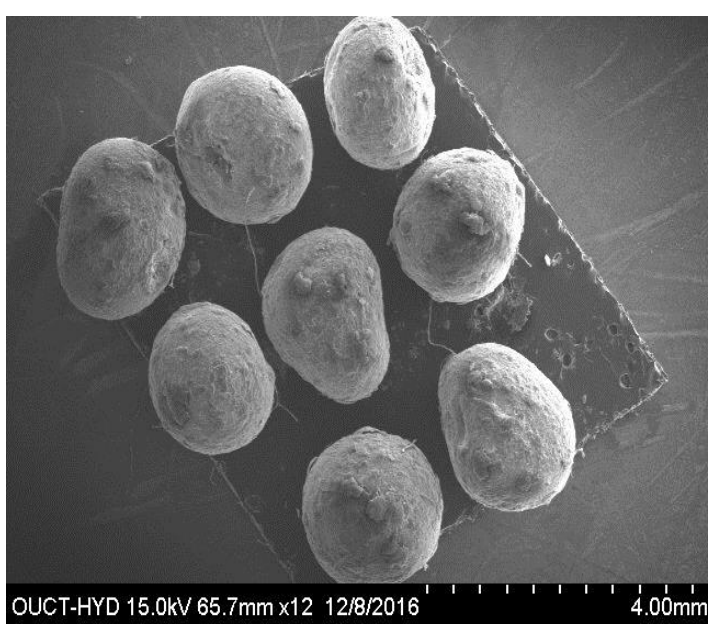

Figure. 5 SEM images of optimized formulation

Table 3. Average diameter, drug entrapment efficiency and \% yield of acyclovir Microspheres

\begin{tabular}{|l|l|l|l|l|}
\hline S. No & $\begin{array}{l}\text { Formulation } \\
\text { code }\end{array}$ & $\begin{array}{l}\text { Average size } \pm \text { SD } \\
(\boldsymbol{\mu m})\end{array}$ & $\begin{array}{l}\text { Entrapment Efficiency } \\
(\boldsymbol{\%})\end{array}$ & $\begin{array}{l}\text { Percent yield } \\
(\boldsymbol{\%})\end{array}$ \\
\hline 1. & S1 & $23.8 \pm 4.58$ & 46.00 & 52.89 \\
\hline 2. & S2 & $28.6 \pm 6.48$ & 54.03 & 57.60 \\
\hline 3. & S3 & $34.7 \pm 5.27$ & 64.25 & 76.38 \\
\hline 4. & F1 & $34.5 \pm 7.23$ & 48.38 & 56.24 \\
\hline 5. & F2 & $20.3 \pm 5.36$ & 54.76 & 60.03 \\
\hline 6. & F3 & $36.7 \pm 7.42$ & 72.90 & 80.23 \\
\hline 7. & F4 & $39.4 \pm 4.09$ & 38.21 & 91.2 \\
\hline
\end{tabular}

Mean \pm SD Where $n=3$

Table 4. In vitro release data of acyclovir microspheres ( 2 and $4 \% \mathrm{w} / \mathrm{v}$ Calcium chloride)

\begin{tabular}{|c|c|c|c|c|c|c|c|c|}
\hline \multirow{2}{*}{$\begin{array}{c}\text { S. } \\
\text { No. }\end{array}$} & \multirow{2}{*}{$\begin{array}{l}\text { Time } \\
\text { (h) }\end{array}$} & \multicolumn{7}{|c|}{ Cumulative \% drug release } \\
\hline & & S1 & $\mathbf{S 2}$ & S3 & F1 & F2 & F3 & F4 \\
\hline 1 & 0 & 0 & 0 & 0 & 0 & 0 & 0 & 0 \\
\hline 2 & 1 & $6.02 \pm 0.36$ & $4.33 \pm 0.22$ & $5.32 \pm 0.46$ & $4.33 \pm 0.16$ & $9.03 \pm 0.31$ & $8.36 \pm 0.72$ & $4.28 \pm 0.63$ \\
\hline 3 & 2 & $14.52 \pm 0.85$ & $8.02 \pm 0.62$ & $7.29 \pm 0.64$ & $7.03 \pm 0.24$ & $13.61 \pm 0.48$ & $15.95 \pm 0.24$ & $6.53 \pm 0.56$ \\
\hline 4 & 3 & $20.03 \pm 0.43$ & $12.38 \pm 0.84$ & $13.54 \pm 0.28$ & $13.28 \pm 0.65$ & $21.43 \pm 0.24$ & $17.82 \pm 0.42$ & $9.76 \pm 0.42$ \\
\hline 5 & 4 & $23.86 \pm 0.52$ & $17.02 \pm 0.56$ & $15.31 \pm 0.42$ & $17.6 \pm 0.46$ & $25.92 \pm 0.55$ & $19.23 \pm 0.25$ & $11.54 \pm 0.12$ \\
\hline 6 & 5 & $29.34 \pm 0.89$ & $22.63 \pm 0.28$ & $21.16 \pm 0.38$ & $22.88 \pm 0.77$ & $26.58 \pm 0.82$ & $21.08 \pm 0.52$ & $13.53 \pm 0.29$ \\
\hline 7 & 6 & $35.15 \pm 0.23$ & $27.76 \pm 0.78$ & $24.73 \pm 0.86$ & $27.72 \pm 0.59$ & $26.84 \pm 0.54$ & $24.69 \pm 0.63$ & $15.84 \pm 0.36$ \\
\hline 8 & 7 & $38.67 \pm 0.54$ & $32.09 \pm 0.29$ & $29.56 \pm 0.54$ & $32.53 \pm 0.16$ & $29.12 \pm 0.43$ & $31.54 \pm 0.36$ & $16.22 \pm 0.48$ \\
\hline 9 & 8 & $46.25 \pm 0.77$ & $35.18 \pm 0.46$ & $3260 \pm 0.23$ & $35.64 \pm 0.52$ & $40.03 \pm 0.22$ & $33.38 \pm 0.92$ & $20.08 \pm 0.71$ \\
\hline 10 & 9 & $52.23 \pm 0.21$ & $42.08 \pm 0.27$ & $34.59 \pm 0.37$ & $37.43 \pm 0.21$ & $45.82 \pm 0.41$ & $36.72 \pm 0.46$ & $25.03 \pm 0.62$ \\
\hline 11 & 10 & $56.25 \pm 0.68$ & $44.11 \pm 0.19$ & $36.03 \pm 0.84$ & $46.64 \pm 0.36$ & $50.08 \pm 0.73$ & $39.83 \pm 0.73$ & $28.43 \pm 0.19$ \\
\hline 12 & 11 & $60.08 \pm 0.32$ & $47.30 \pm 0.48$ & $39.89 \pm 0.67$ & $54.38 \pm 0.52$ & $54.03 \pm 0.34$ & $40.06 \pm 0.44$ & $32.27 \pm 0.37$ \\
\hline 13 & 12 & $61.66 \pm 0.56$ & $49.33 \pm 0.43$ & $40.65 \pm 0.74$ & $66.42 \pm 0.18$ & $57.34 \pm 0.42$ & $43.75 \pm 0.28$ & $55.83 \pm 0.33$ \\
\hline & & & & +8 & here $n$ & & & \\
\hline
\end{tabular}




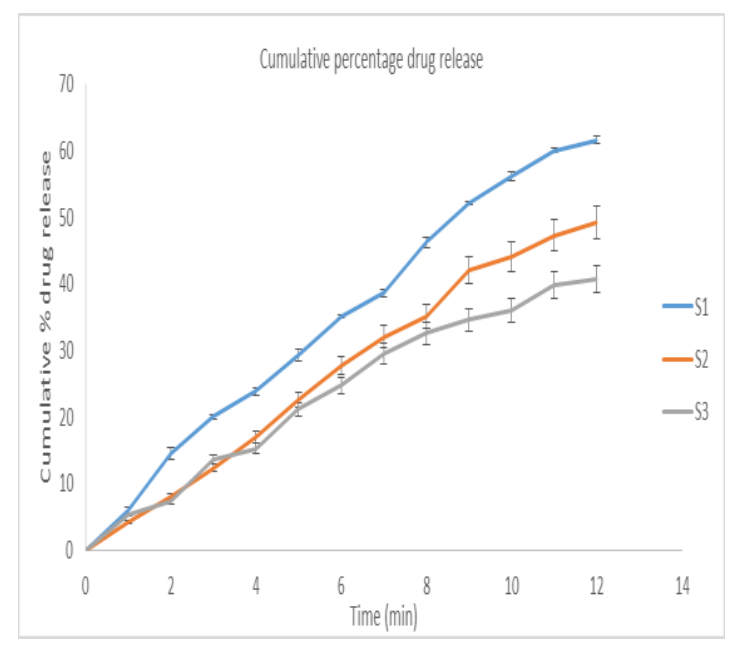

Figure 6. Drug release from S1 to S3

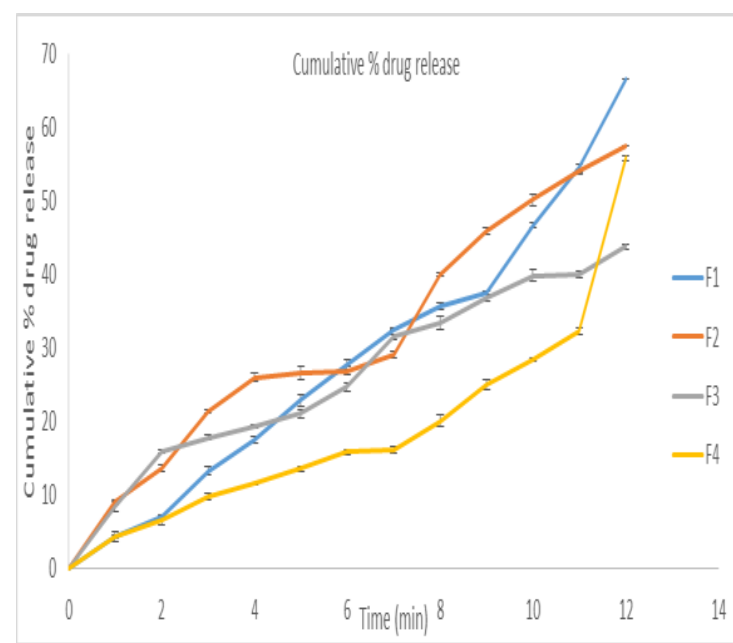

Figure 7. Drug release from $\mathrm{F} 1$ to $\mathrm{F} 4$
S3 Formulation showed $40.65 \%$ cumulative drug release at the end of 12 hours while S1 formulation showed $61.66 \%$ cumulative drug release at the end of 12 hours. This is because with the increase in polymer concentration the free drug concentration on the surface of microspheres will be decreased and more drugs get entrapped in the microspheres and drug gets released slowly. The cumulative $\%$ drug release from $\mathrm{F} 1$ formulation is $66.42 \%$ at the end of 12 hours while cumulative $\%$ drug release from $\mathrm{F} 4$ formulation is $55.83 \%$ at the end of 12 hours. The drug release from $\mathrm{S}$ formulations and $\mathrm{F}$ formulations were mainly depend on amount of sodium alginate and the concentration of calcium chloride. This is because with the increase in cross linking agent concentration more drug gets entrapped in the microspheres and the microspheres formed are more intact when compared to other formulations. The microspheres and the microspheres formed are more intact when compared to other formulations.

The drug release data was best explained by zero order equations, $\mathrm{R}^{2}$ for zero order and first order were obtained at 0.9896, 0.3476 (F3) respectively. Based on the particle size, entrapment efficiency, drug release and $\mathrm{R}$ square value it was confirmed that the optimized formulation (F3) follows zero order and according to Korsemeyer-Peppas ( $\mathrm{n}=$ $0.9855, \mathrm{r}^{2}=0.9489$ )it was non Fickian. To ascertain the drug release mechanism the in vitro release data were also subjected to Higuchi's diffusion plot, Hixson Crowell plot and Peppas plot and the correlation coefficient values were found to be $0.5871,0.0362$ and 0.9489 respectively in table (5) and figure $(8,9,10,11)$.

Table 5. Regression co-efficient $\left(\mathbf{r}^{2}\right)$ values of different kinetic models and diffusion exponent (n) of Peppas model for optimized formulation (F3)

\begin{tabular}{|l|l|l|l|l|l||}
\hline \hline Formulation & Zero order & First order & Higuchi Matrix & \multicolumn{2}{|c|}{ Korsemeyer- Peppas } \\
\hline & $\mathrm{r}^{2}$ value & $\mathrm{r}^{2}$ value & $\mathrm{r}^{2}$ value & $\mathrm{r}^{2}$ value & $\mathrm{N}$ value \\
\hline F3 & 0.9896 & 0.3476 & 0.5871 & 0.9489 & 0.9855 \\
\hline
\end{tabular}

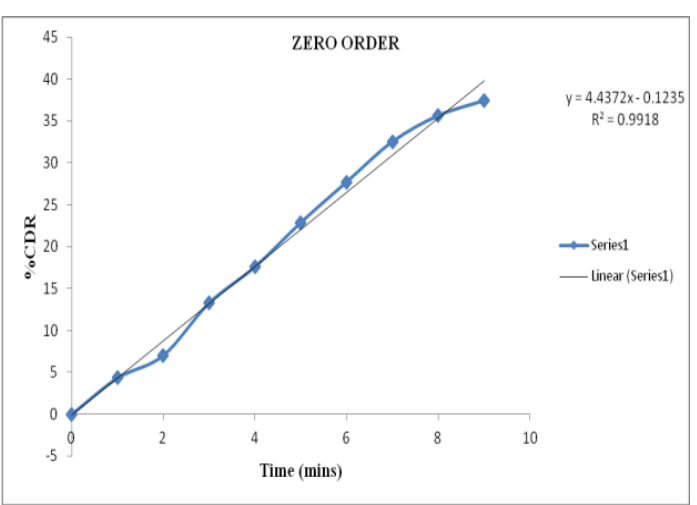

Figure 8. Zero order plot of F3

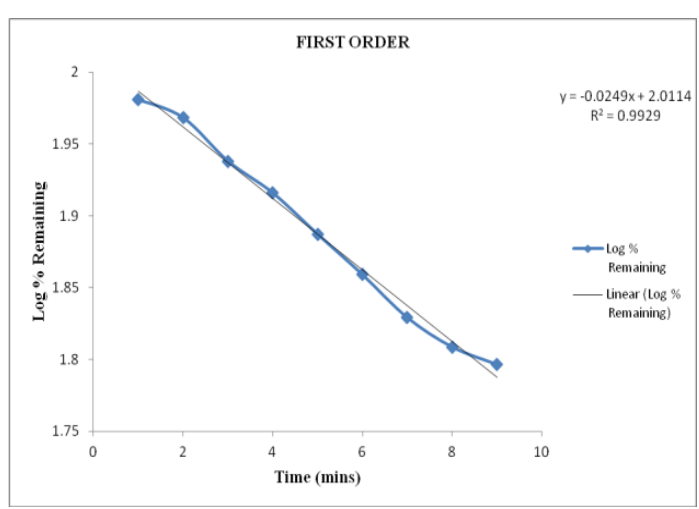

Figure 9. First order plot of F3 


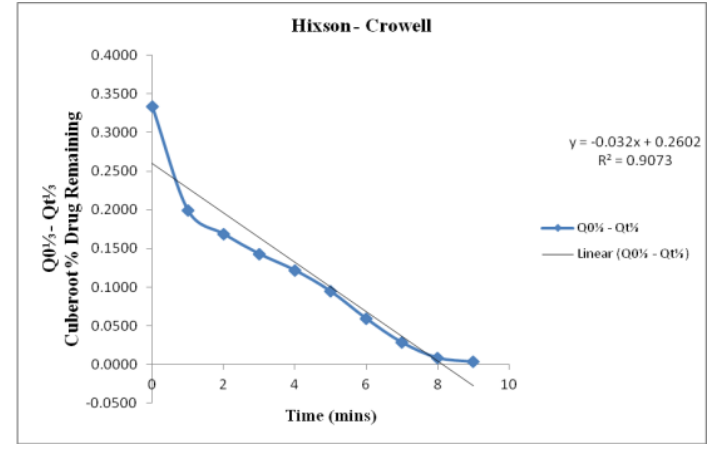

Figure 10. Hixson- Crowell plot of F3

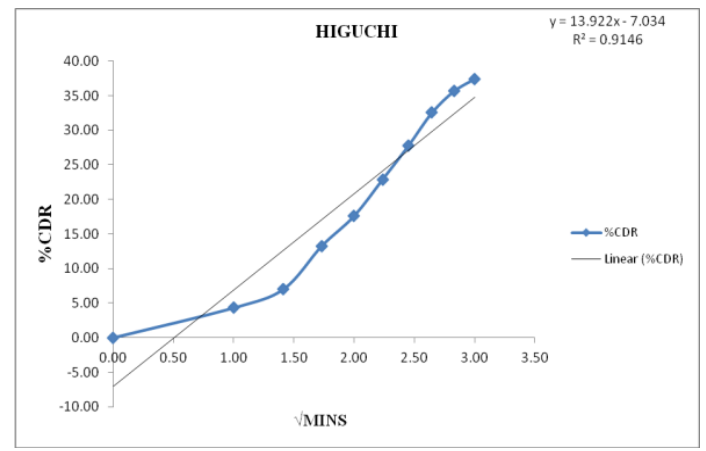

Figure 11. Higuchi plot of F3

\section{Conclusion}

From the above experimental results, it can be concluded that Preformulation studies, like solubility and UV analysis of ACV and melting point were complied with standards. The FTIR Spectra's revealed that, there was no interaction between polymer and ACV. The polymer used is compatible with the ACV. Oral controlled release of ACV can be achieved by ionic gelation by using polymer chitosan and sodium alginate. The Surface smoothness of the ACV microspheres was increased by increasing the polymer concentration, which was confirmed by SEM. As the drug to polymer ratio was increased, the mean particle size of ACV microspheres was also increased. Entrapment efficiency increases with an increase in the polymer concentration and also with an increase in calcium chloride concentration. From the results it can be inferred that there was a proper distribution of $\mathrm{ACV}$ in the microspheres and the deviation was within the acceptable limits. The study also indicated that the amount of drug release decreases with an increase in the polymer concentration. The in vitro performance of ACV microspheres showed prolonged and controlled release of the drug. The co-efficient of determination indicated that the release data was best fitted with zero order kinetics. From the study it is evident that promising sustained release microspheres of ACV may be developed from ionic gelation techniques by using polymers chitosan and sodium alginate.

\section{References}

1. Arshad Bashir Khan. Formulation and invitro evaluation of Acyclovir mucoadhesive microspheres for intravaginal application. Indian journal of pharmaceutical sciences, 2014; 10(3): 35-46

2. Dandagi PM, Manvi FV, Gadad AP, Mastiholimath VS, Patil MB, Balamuralidhara V. Micro encapsulation of Verapamil hydrochloride byionotropic gelation technique. Indian journal of pharmaceutical sciences, 2004; 66(5): 631635

3. Nair R, Reddy B, Kumar C, Kumar K. Application of Chitosan microspheres as drug carrier: A Review. Journal of pharmaceutical sciences and research, 2009;12: 1-12

4. Hirano S, Seino H, Akiyama Y, Nonaka I. Chitosan: a biocompatible biomaterial for oral and intravenous administration. Progress in Biomedical Polymers, Plenum Press, 1990; 283-290.

5. Sahoo SK, Dalai SR, Pani NR, Barik BB. Formulation and in vitro evaluation of alginate beads of aceclofenac byionotropic gelation technique. Indian Drugs, 2007; 44(11): 324-327.

6. Kas H.S. Chitosan: properties, preparation and application to micro particulate systems. Journal of Microencapsulation, 1997; 689-711.

7. Pavani S, Deepak K, Sujitha H. Preparation and in vitro evaluation of chitosan microspheres of eplerenone. International journal of pharmacy and pharmaceutical sciences, 2013; 5 (3): 226-229

8. Jameela SR, Misra A, Jayakrishnan A. Cross-linked chitosan Microsphere as carrier for prolonged delivery of macromolecular drugs. Journal of biomaterial science and Polymer, 1994; 6(7): 621-632

9. Madhavi K. Preparation and characterization of Eudragit coated Chitosan Piroxicam microspheres intended for the treatment of rheumatoid arthritis. Pharmaceutica analyticaacta, 2016; 7(6): 2153-2435

10. Desai KG, Park HJ. Study of gammairradiation effects on chitosan micro particles. Drug delivery, 2006; 13:39-50.

11. Hejazi R, Amiji M. Chitosan-based gastrointestinal delivery systems. Journal of controlled release, 2003; 89: 151-165

12. Mathiowitz E, Kreitz MR, Brannon-Peppas L. Micro encapsulation, Encyclopedia of Controlled Drug Delivery, New York, NY: John Wiley and Sons, Inc., 1999; 493-546. 